\title{
A Methodology for the Quantitative Assessment of the Primary Social Impact of Agricultural Technologies
}

\author{
Deepu Mathew and P. V. Habeeburrahman \\ Krishi Vigyan Kendra, Kerala Agricultural University, Tavanur 679 573, India \\ E-mail: deepuhort@gmail.com
}

KEYWORDS Agricultural extension; hierarchical clustering; impact analysis; social impact; technology
dissemination

ABSTRACT Present methodologies for the assessment of the social impact of agricultural technologies and their modes of extension are merely comparative or often qualitative. A hierarchical clustering based impact assessment tool is detailed in this paper. Social impacts of thirty-nine agricultural technologies extended by Krishi Vigyan Kendra (Kerala Agricultural University) were quantified using the scores based on the number of participants and the level of adoption. Common anomalies in biometric analyses caused by the numerical size of data were mitigated through transformation of data within a mode of extension into a $0-1$ scale. Transformed data were given the weightage based on the level of adoption and further used in the hierarchical clustering to obtain the bi-dimensional dendrogram presenting the comparative impact of technologies as well as modes of extension.

\section{INTRODUCTION}

The impact of extension practices is influenced by factors relating to technology and other inputs, infrastructural facility, extension system, extension personnel, clients and government policy. Because of these factors, an effective practice in one place may not be that effective in other places and vice versa (Vasanthakumar, 2004). However, it is essential to measure the impact in quantitative terms to formulate strategies for enhancing the efficiency through cause-causation basis (Maji and Haque, 1979). The impact of agricultural technologies is often quantified in terms of adoption, income or area of practice (Rogers, 1995). This methodology demands precise data on potentiality as well as the extent of adoption so as to reach an adoption quotient (Ray, 2004) and further, many years of observation. Rather simpler methods of analysis of impact of various technologies involve either or combination of farm advisory, field visits, visits to knowledge centres, income generation, quantifiable responses to mass media, sales in an approved outlet, new entrepreneurs, preference of extended technology over the ruling alternative, secondary and tertiary diffusion as understood from feedback and personal interviews following prefixed schedules (Aravindakshan et al., 2003). Credibility of farmers' information sources such as demonstrations, resource persons, progressive farmers, TV, radio, folders, bulletins and newspapers is also scored based on the surveys (Singh, 1971). Apart from this, the impact of individual ToT methodologies such as radio talks is assessed through simple surveys (Sandhu, 1970). However, all these studies confine with either quantitative or qualitative ranking (Sandhu, 2003). In this paper, we detail a simplified methodology for the analysis of immediate social impact of various technologies as well as the involved methodologies, simultaneously. Other advantages of this methodology are the flexibility to use both quantitative as well as qualitative outputs simultaneously with the weightage for the levels of adoption/ diffusion and analysis based the response within any defined time frame (Mathew, 2004).

\section{MATERIALS AND METHODS}

Consortium of agricultural technologies extended by the Krishi Vigyan Kendra Malappuram (Kerala Agricultural University) was taken as the model for demonstrating the methodology for quantification and graphical representation of social impact. Thirty-nine technologies as presented in Table 1 were extended using 18 extension methodologies (Front Line Demonstrations, On Farm Testing, popular articles, extension literature, training for farmers and extension functionaries, field days, seminars, farmers' field schools, demonstrations, field visits, radio talks, TV coverage, newspaper coverage, telephonic farm advisory, KVK visits 
by farmers, advisory services, vocational trainings and farmer-farmer interactions), categorised under 8 heads based on their assumed impact on social mass. Front Line Demonstrations and On Farm Tests were more aptly equated with the increase in area of practice. The popular articles and radio, TV and newspaper coverage were scored based on the average impact report by the respective audience research cells. The levels of adoption were decided as described by Dahama and Bhatnagar (1987). All 18 methodologies were included under the primary level of adoption to give no impact weightage. Adoption of technology was allotted a weightage of 1.5 , practice with 2.0 and highest levels viz. commercialisation as qualitative and increase in area or number of practicing people as quantitative measures with 2.5 each in the analysis. The comparative weightages were optimised based on the clustering pattern of the treatments since a higher range may lead to failure in sub-clustering at low levels of adoption. However, the weightages were applied only on the necessary transformation of data, before analysis.

To solve the higher numeral problem in usual principal component, $\mathrm{D}^{2}$ or hierarchical analyses, data within all modes of extension were independently transformed to a $0-1$ scale following $\left(\mathrm{V}-\mathrm{V}_{\min }\right) /\left(\mathrm{V}_{\max }-\mathrm{V}_{\text {min }}\right)$ where, $\mathrm{V}$ was the score against any technology under a particular method of extension, $\mathrm{V}_{\text {min }}$ and $\mathrm{V}_{\text {max }}$, the values for the technologies receiving minimum and maximum scores under the same method of extension respectively (Mathew et al., 2007). The transformed and weighted values were analysed using hierarchical clustering.

\section{RESULTS AND DISCUSSION}

Figure 1 presents a bi-dimensional dendrogram of the impact of 39 technologies extended by KVK Malappuram. Both method of extension and score of impact were taken into consideration for clustering.

Cluster (i) was constituted with 13 technologies that were extended mainly through trainings and advisory services. Total score within the cluster varied from 25 to 204 . Cluster (ii) had 3 technologies, which had the increase in area of adoption as the major scoring factor. From these clustering habits it is clear that not only the scoring but the mode of extension is also the deciding factor in clustering. Cluster (iii) had only 1 technology whose major contributors were adoption of technology and popular articles. Cluster (iv) had only 2 technologies, which were characterised by extension literature as major contributor for scoring. Cluster (v) had 3 technologies whose major contributor was newspaper coverage followed by increase in area, training and advisory services. Increase in area, due to its highest weightage, had pushed up the scores within the cluster from 542 to 2025 . Cluster (vi) had 2 technologies with TV coverage as major contributor and cluster (vii) had 2 technologies decided by the increase in area, training and advisory services. It may be noted that the lower part of the cluster (i) had the same methods of extension but with lesser scores. Cluster (viii) had 4 technologies whose major contributor was radio programme. Within the cluster, an ascending order was followed based on the total scores. Cluster (ix) holds 2 technologies that were primarily guided by TV mode of extension. But within the cluster, technologies 27 and 11 differed substantially since the subsidiary modes with high level scoring influence were vocational training and adoption respectively. This factor made cluster (ix) distinct from cluster (vi). Cluster (x) had 2 technologies, which were highly distinct from others, though mainly contributed from radio talks, in that they had high scores from publication, extension literature and commercialisation of technologies. Cluster (xi) with 3 technologies was distinct in it self with very high scores ranging from 10132 to 28230 and decided by increase in area, trainings and advisory services. At an earlier stage itself, individual and group contacts were proved effective in diffusion of innovations leading to adoption. During the Training and Visit period, personnel contact with selected farmers was very intensive resulting in increased productivity (Shingi et al., 1982). As the very high scores in cluster (xi) point, increase in area brought either by personal contact or advisory is an immediate indication of utmost extension efficiency. Further, organization of farmers into groups and institutionalization of contact farmers and regularity of meeting between contact farmers and extension staff is worthwhile and adds value to the extension practice (Biscoe, 1991). Technologies such as 34, 15, 32 and 20 also had the same modes of extension. But it is clear from the clustering that the effect of total scores on 


\section{Rescaled Distance Cluster Combine}

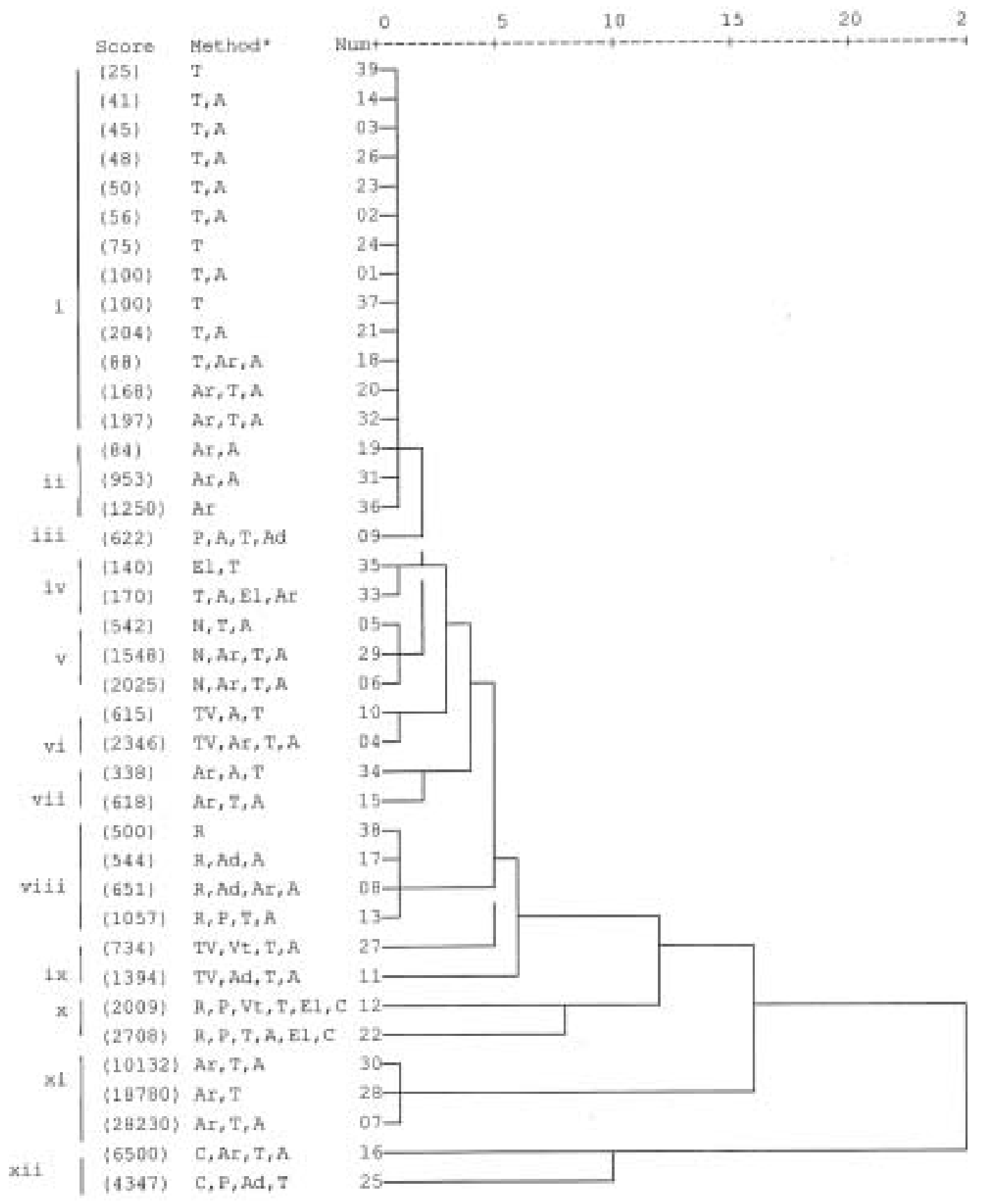

Fig. 1. Dendrogram using Average Linkage (weightage - 1, 1.5, 2, 2.5 and 2.5)

(A-Advisory services, Ad-Adoption of technology, Ar-increase in area, C-Commercialisation of technology, ElExtn Literature, N-Newspaper, P-Popular article, R-Radio, T-Training, TV-Television, Vt-Vocational training)

* Methods of extension are arranged in the order of extend of contribution to score 


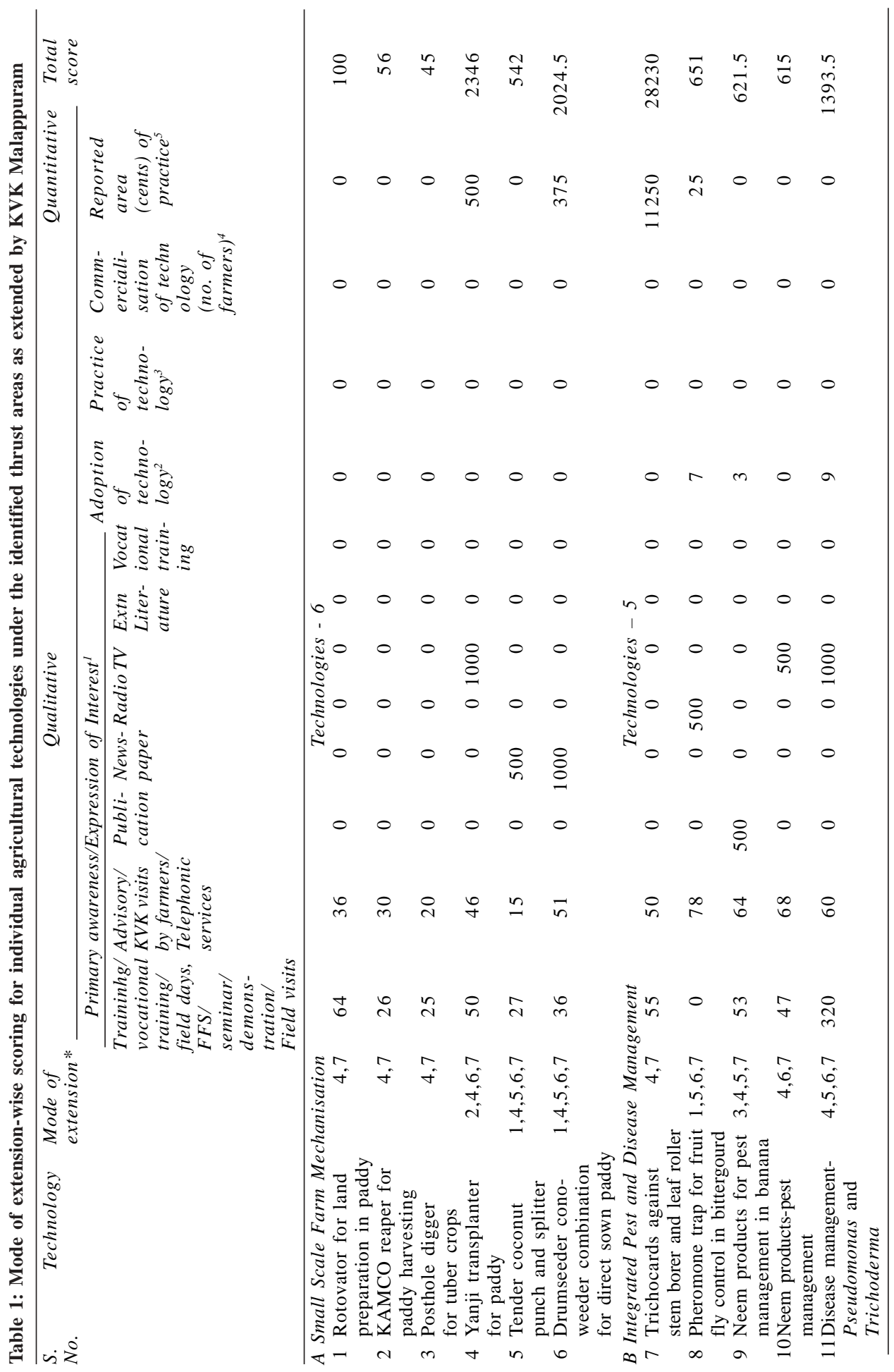




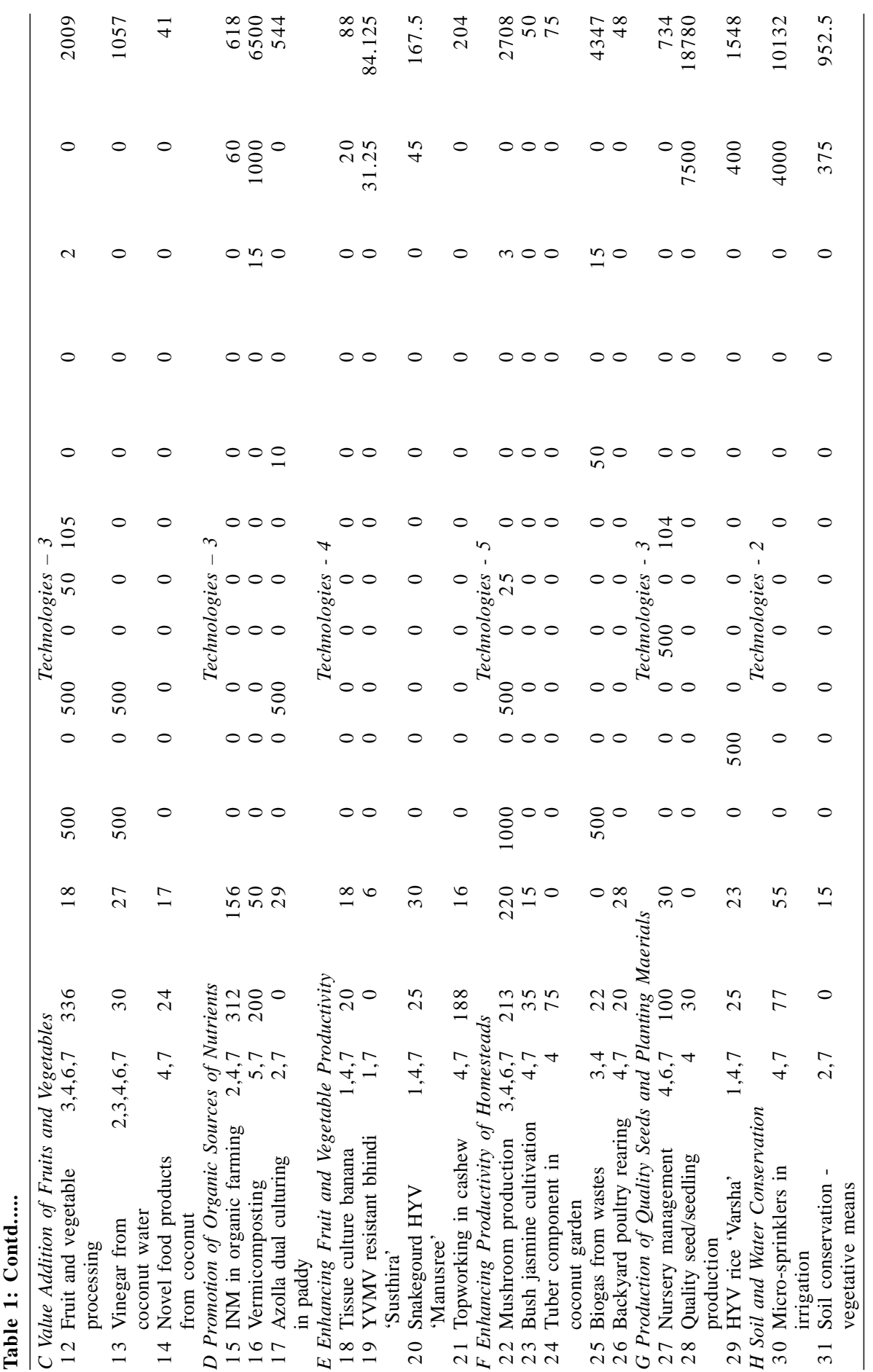




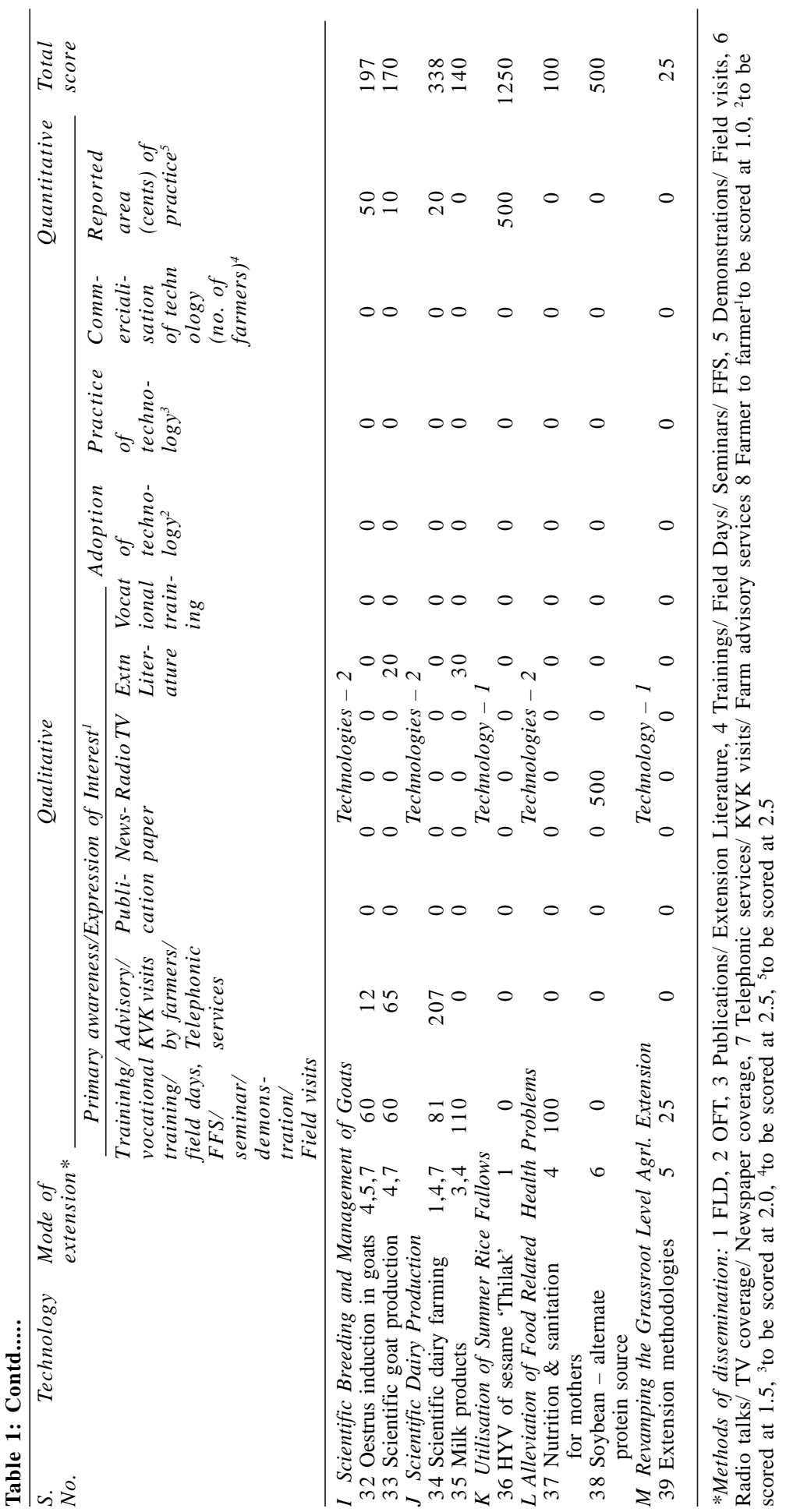


the clustering is equally profound with mode of extension. Cluster (xii) also had 2 technologies, the scores of which were mainly the contribution from commercialisation of technology.

From the results it is evident that hierarchical clustering of transformed and then weighted data, is capable to arrive at social impact of different technologies and extension strategies. This methodology simultaneously considers the mode as well as the impact of the programme on the adoption rate. The effective extension practices were delineated based on their impact in terms of adoption and productivity increase. As the practices are dependent on many factors, in-depth understanding of the situation is required, in addition to the competency of extension workers in handling them (Prakash and Nehru, 2004). A primary appreciation is feasible with all kinds of available outputs through this simplified methodology.

\section{REFERENCES}

Aravindakshan, K., S. J. Menon, R. M. Prasad and A. I. Jose. 2003. Impact Assessment of ATIC, Kerala Agricultural University, Mannuthy, India.

Biscoe, J. 1991. "Training and Visit - Resource management and not extension. The World bank and message factory." Journal of Extension Systems, 1: $30-35$.

Dahama, O. P. and O. P. Bhatnagar. 1987. Education and Communication for Development, Oxford \& IBH Publishing Co. Pvt. Ltd., New Delhi.

Maji, C. C. and T. Haque. 1979. "Efficiency of agricultural extension in transfer of technology and income generation before and after the green revolution in India." Indian Journal of Agricultural Extension, 34: 1-10
Mathew, D. 2004. Genetic Divergence, Morphological and Molecular Characterisation and Conservation of Germplasm in Capsicum spp. Doctoral Thesis submitted to University of Agricultural Sciences, Bangalore, India

Mathew, D., T. Parimelazhagan, S. Gomez and Z. Ahmed. 2007. "Characterisation of seabuckthorn genetic resources in India using morphological descriptors." Plant Genetic Resources Newsletter, 149: 1-5

Prakash, R. and S. M. Nehru. 2004. "Effective extension practices in technology transfer in rice-Research evidences from Kerala", (pp. 54-58) in Proceedings of National Seminar on Scaling up of Good Extension Practices in Rice Production Systems. September 30-October 1, 2004, Pattambi, Palakkad District, Kerala, India, Kerala Agricultural University, India,

Ray, G. L. 2004. Extension Communication and Management, $5^{\text {th }}$ Edition, Ludhiana: Kalyani Publishers, Pp. 199-202

Rogers, E. M. 1995. Diffusion of Innovations. New York: The Free Press.

Sandhu, A. S. 1970. Characteristics, Listening Behaviour and Programme Preferences of the Radio Owning Farmers in Punjab. Doctoral Thesis, Indian Agricultural Research Institute, New Delhi, India

Sandhu, A. S. 2003. Text Book on Agricultural Communication: Process and Methods, New Delhi: Oxford \& IBH Publishing Co. Pvt. Ltd.

Shingi, P. M., V. R. Gaikwad, R. Sulaiman and J. Vasanthakumar. 2004. State of the Indian Farmer - A Millennium Study: Agricultural Extension. New Delhi: Govt. of India and Academic Foundation.

Singh, S. N. 1971. "Relative effectiveness of audiovisual aids." Indian Journal of Extension Education, 8 (3-4): $12-19$

Vasanthakumar, J. 2004. "Extension practices in transfer of technology - Conceptual note", ( pp. 46-47) in Proceedings of National Seminar on Scaling up of Good Extension Practices in Rice Production Systems. September 30-October 1, 2004, Pattambi, Palakkad District, Kerala, India, Kerala Agricultural University, India. 